\title{
ON THE INFLUENCE OF THE ELECTRON COMPONENT OF LATTICE DEFORMATION ON LOCALIZED STATES IN CRYSTALS WITH DISLOCATIONS
}

\author{
R. M. Peleshchak ${ }^{1}$, B. A. Lukiyanets ${ }^{2}$ \\ ${ }^{1}$ The Ivan Franko Pedagogical University, \\ 34 I. Franko Str., Drohobych, UA-293720, Lviv region, Ukraine \\ ${ }^{2}$ State University "Lvivs'ka Politekhnika", \\ 12 Bandera Str., Lviv, UA-290646, Ukraine \\ (Received December 11, 1998)
}

\begin{abstract}
Using earlier proposed method of selfconsistent investigation of the lattice strain the localized electron states in the vicinity of an edge staight linear dislocation are analyzed, namely the dependence on the value of the electron-deformation interaction. It is shown that the depth of the state location nonmonotonously depends on such an interaction.
\end{abstract}

Key words: linear dislocation, electron-deformation interaction, localized electron states.

PACS number(s): 71.10.-w

It is known that the mechanical distortion of a crystal lattice caused by dislocations, twinning planes and impurities can essentially change its electron properties. The study of these effects is an important aspect of both experimental and theoretical investigations [1-4]. A similar task in a crystal with dislocation was considered in [5]. A dislocation was presented by the $\delta$-like distortion on the axis in its core. For the description of the distortion let us use $U(r)=\operatorname{Sp} U=\left(\Omega(x)-\Omega_{0}\right) / \Omega_{0}\left(\Omega_{0}\right.$ is a crystal cell volume of the undeformed lattice). $U>0$ corresponds to the lattice extention and $U<0$ to its shortening. In [1] it is shown that in the $U>0$ case $(U<0)$ in the electron spectrum the localized splitted out of the bottom (top) of the band states appear. The influence of the potential slowly changing away from the distortion axis on the localized states was investigated in $[2,5]$. According to more accurate theory which takes into account electron-deformation interaction [4, 6, 7] the parameter of the lattice deformation essentially depends on the degree of the conduction band population. Below we analyze the electron spectrum of defect crystal with straight linear dislocation in the frame of the model taking into account the electron-deformation interaction. We consider an isotropic metal with a dislocation with an axis along OZ and with a Burger vector $b$ along OX. Then all-round mechanical strain out of the dislocation core region in cylindrical coordinates with polar coordinates $(\rho, \theta)$ in XOY plane can be written in the form [8]:

$$
\sigma_{m}(\rho, \theta)=\mathrm{S} p \widehat{\sigma}_{m}=-\frac{2|b|}{3 \pi} \frac{1+\nu}{1-\nu} C_{66} \frac{\sin \theta}{\rho}, \rho \geq \rho_{0}
$$

Where $\nu$ is Poisson's coefficient, $C_{66}$ is a metal elastic modulus, $\rho_{0}$ is a radius of a dislocation $(\rho=(1-2) a$, $a$ is a crystal parameter). The Hamiltonian of the system in the site representation is:

$$
\begin{aligned}
\widehat{H} & =\sum_{j \sigma}\left[W+S U\left(r_{j}\right)\right] c_{i \sigma}^{+} c_{i \sigma}+\sum_{i j \sigma} \lambda_{i j} c_{i \sigma}^{+} c_{j \sigma} \\
& +\frac{1}{2} \sum_{i} C \Omega_{0} U^{2}\left(r_{i}\right)+H_{c}
\end{aligned}
$$

Here the 1 st term is a Hamiltonian of an electron on the site $r_{i}$ with taking into account a change of its energy by deformation ( $S$ is a constant of deformation potential, $W$ is a reference to the origin of the energy chosen in the middle of the band). The 2 nd term is an electron mixing of the $i$-th and $j$-th sites in nondeformed crystal; the $3 \mathrm{rd}$ one is a potential energy of the elastic deformed crystal ( $C$ is an elastic modulus). The 4 th term is Coulomb interaction. $\left(c_{i \sigma}^{+}, c_{i \sigma}\right.$ are fermion operators). The parameter of the total deformation $U(r)$, caused by mechanical strain $\sigma_{m}\left(r_{i}\right)$ consists of electron and mechanical components. Outside the region of the dislocation it may be obtained from the condition of the mechanical equilibrium [9]:

$$
\left\langle\frac{\partial \hat{H}}{\partial U}\right\rangle=\sigma_{m}(r) V
$$

where $V$ is the crystal's volume. Considering (2), condition (3) in momentum representation takes the form of

$$
U(r)=-\frac{S}{C \Omega_{0}} \sum_{k k^{\prime} \sigma}\left\langle c_{k \sigma}^{+} c_{k^{\prime} \sigma}\right\rangle \exp \left[-i\left(k-k^{\prime}\right) r\right]+U_{m}(r)
$$

where the first term describes the electron component of the total deformation $U(r)$. The mechanical one, $U_{m}(r)$, as a result of the mechanical strain in cylindrical coordinates is 


$$
U_{m}(\rho, \theta, z)=\operatorname{S} p \widehat{\sigma}_{m}=-D \frac{\sin \theta}{\rho}
$$

with

$$
D=\frac{2 C_{66}}{3 C} \frac{|b|}{\pi} \frac{1+\nu}{1-\nu}
$$

From (4) it follows that the electron component of deformation is accompined by the determination of the $\left\langle c_{k \sigma}^{+} c_{k^{\prime} \sigma}\right\rangle$ correlator which is connected with the electron conduction band concentration

$$
n(r)=\sum_{m} \frac{\psi_{m}^{*}(r) \psi_{m}(r)}{\exp \left[\beta\left(\lambda_{m}-\mu\right)\right]+1}
$$

by Fourier-transformation. In $(6) \psi_{m}(r)$ is a solution of
Schrodinger equation

$$
\left[\nabla_{r}^{2}-\frac{S}{\alpha} U(r)+\frac{e}{\alpha} \varphi(r)\right] \psi_{m}(r)=-\frac{1}{\alpha} \lambda_{m} \psi_{m}(r) .
$$

Here $\alpha=\frac{\hbar^{2}}{2 m}$ ( $m$ is an effective mass) and $\lambda_{m}$ is an energy counted off $\lambda_{0}$. The last term in the left hand of (7) is the electrostatic energy caused by the charge redistribution. The potential $\varphi(r)$ may be obtain from Poisson equation

$$
\nabla_{\rho \theta z}^{2} \varphi-g^{2} \varphi=\nabla_{\rho \theta z}^{2} S U_{m}=\frac{2 D S}{\rho_{0}^{2}} \delta\left(\rho-\rho_{0}\right) \sin \theta
$$

Here $g=\frac{e}{\left(R_{s} / \epsilon \epsilon_{0}\right)^{1 / 2}}$, i.e. it is a value inverse to an effective radius of screening dependent on the band population $n$, the elastic modulus and the effective mass. Here

$$
R_{s}=\frac{1}{\alpha}\left(\frac{3 n_{0}}{8 \Omega_{0} \pi^{4}}\right)^{1 / 3} \frac{\sqrt{1+\left(\frac{n_{m}}{9 \Omega_{0} \pi^{4}}\right)^{1 / 3} \frac{S^{2}}{\alpha C}}}{1-\frac{3}{2} \frac{S^{2}}{\alpha C}\left(\frac{n_{m}}{9 \Omega_{0} \pi^{4}}\right)^{1 / 3} \sqrt{1+\left(\frac{n_{m}}{9 \Omega_{0} \pi^{4}}\right)^{1 / 3} \frac{S^{2}}{\alpha C}}}
$$

where

$$
n_{m}=n_{0}\left[1+\left(\frac{n_{m}}{9 \pi^{4}}\right)^{1 / 3} \frac{S^{2}}{\alpha C}\right]^{3 / 2}
$$

- is an average total concentration of the electron in a crystal in consideration of electron-deformation interaction.

The system of equations (4), (5)-(7) and equation

$$
\frac{\Omega_{0}}{V} \int n(r) d r=\breve{n}, 0 \leq \breve{n} \leq 2
$$

which allows to determine chemical potential were solved in $[4,6,10]$ ( $\left.\check{n}=n_{m} \Omega_{0}\right)$. According to [10] the potential $\varphi(r)$ is

$$
\varphi(\rho, \theta, z)=-\frac{2 D S}{\rho_{0}} \sin \theta\left\{\begin{array}{l}
K_{1}\left(g \rho_{0}\right) I_{1}(g \rho), \rho \in\left[0, \rho_{0}\right] \\
I_{1}\left(g \rho_{0}\right) K_{1}(g \rho), \rho \in\left[\rho_{0}, \infty\right)
\end{array}\right.
$$

where $K_{1}(g \rho)$ is McDonalds function, and $I_{1}(g \rho)$ is the first kind Bessel function of the first order [12]. A strain of the crystal in the vicinity of the edge core in- duced by both its mechanical component $U_{m}(\rho, \theta)$ and a component originating from the electron redistribution $\triangle n(\rho, \theta, z)=n(\rho, \theta, z)-n_{m}$ is defined by relation [10]:

$$
\triangle U(\rho, \theta, z)=-\frac{S}{C} \triangle n(\rho, \theta, z)+U_{m}(\rho, \theta)
$$

where

$$
\triangle n(\rho, \theta, z)=-S R_{s} D \sin \theta\left[\frac{2}{\rho_{0}} I_{1}\left(g \rho_{0}\right) K_{1}(g \rho)-\frac{1}{\rho}\right] .
$$

Note that the analysis (in the frame of quasiclassic approximation) is justifiable for the $\mu a^{2} \leq 0.01$ case [3] ( $a$ is some characteristic length of the problem, f.ex., a lattice parameter). The existence of regions with negative values of the potential $S U(r)$ can be risen to localized states. Analyze such a possibility. As far as the potential of dislocation (5) has a two-dimensional character Schrödinger equation with such a potential is a two-dimensional task. Let $A(E)$ be a region where inequality

$$
S U<E \equiv \epsilon-\lambda_{0}-\alpha k_{z}^{2}
$$

is realized. Define $G(E)$ as a spatial density per unit sur- 
face at $S U=0$. For smoothing a potential well it takes the form of

$$
G(E)=\frac{d N}{d E}=\int_{\triangle U<0} G_{0}(E-S U) d A(E) .
$$

In the two-dimensional case $E\left(k_{x y}\right)=\alpha k_{x y}^{2}$ and $G_{0}=$ $2 \pi m / h^{2}$. Then

$$
\frac{d N}{d E}=\frac{2 \pi}{\hbar^{2}} m A(E)
$$

Define the boundary of region $A(E)$. From equality $S \triangle U=E$ and equation (13) we have

$$
E=\frac{S D}{\rho} \sin \theta\left[\frac{S^{2} R_{s}}{C}\left(\frac{2 \rho}{\rho_{0}} I_{1}\left(g \rho_{0}\right) K_{1}(g \rho)-1\right)-1\right]
$$

For the elastic strain at $\rho>\rho_{0}$

$$
K_{1}(g \rho)=\frac{1}{2 g \rho}+0\left((g \rho)^{-3 / 2}\right)
$$

and $E$ from (18) takes the form of

$$
E=\frac{S D}{\rho}(q-1) \sin \theta
$$

where

$$
q=\frac{S^{2} R_{s}}{C} \frac{\sqrt{\pi}}{g \rho_{0}}\left(I_{1}\left(g \rho_{0}\right)-1\right)
$$

is a parameter taking into account the influence of the electron-deformation interaction on the level of the electron states localization. In this case

$$
\begin{aligned}
A(E) & =\iint \rho d \rho d \theta=\frac{1}{2 E^{2}} S^{2} D^{2}(q-1)^{2} \int_{0}^{\pi} \sin ^{2} \theta \\
& =\frac{\pi S^{2} D^{2}(q-1)^{2}}{4 E^{2}}
\end{aligned}
$$

and (17) in consideration of (20) takes the form of

$$
\frac{d N}{d E}=\frac{\pi^{2} m S^{2} D^{2}}{2 \hbar^{2} E^{2}}(q-1)^{2}
$$

and

$$
E_{N}=-\frac{\pi^{2} m S^{2} D^{2}(q-1)^{2}}{2 \hbar^{2}} \frac{1}{N}, N=1,2,3 \ldots
$$

From (24) it follows that localized states behave as a $\sim N^{-1}$ decreasing sequence. It coinsides with the results of $[5]$.

From (24) the conclusions follow that

- for "weak" electron-deformation interaction, $q \in$ $[0,1]$, the localized states are closer to the band bottom than in the case of such an interaction. If $q$ tends both from the right and from the left to one, $E$ tends to the band bottom;

- for the "large" $q, q>2$, or its negative value (such a situation at certain correlations between $n_{m}, S$, $C, m$ according to (9), (21) is possible) localized states are depeer and the absolute value $q$ increasingly tends to lower such states.
[1] A. M. Stoneham, Theory of defects in solids (Clarendon press, Oxford, 1975).

[2] A. M. Kosevich, Dislokatsyi v tieorii uprugosti (Dislocation in theory of elasticity) (Naukova dumka, Kyiv, 1978).

[3] A. L. Polyakova, Deformatsyi poluprovodnikov i poluprovodnikovykh priborov (Deformation of semiconductors and semiconductors devices) (Nauka, Moscow, 1979).

[4] I. V. Stasyuk, R. M. Peleshchak, Ukr. Fiz. Zh. 36, 1744 (1991).

[5] I. M. Lifshits, H. I. Pushkarov, Pis'ma Zhurn. Eksp. Teor. Fiz. 11, 456 (1970).

[6] I. V. Stasyuk, R. M. Peleshchak, Ukr. Fiz. Zh. 39, 856
(1994).

[7] I. V. Stasyuk, R. M. Peleshchak, preprint IFKS-92-174, Kyiv (1992).

[8] T. Sudzuki, H. Esinaga, C. Takeuti, Dinamika dislokatsii i uprugost' (Dynamics of dislocations and elasticity) (Mir, Moscow, 1989).

[9] L. D. Landau, I. M. Lifshits, Tieoriia uprugosti (Theory of elasticity) (Nauka, Moscow, 1965).

[10] R. M. Peleshchak, B. A. Lukiyanets, Pis'ma Zh. Tekh. Fiz. 24, 32, 1988. bibitem b11 D. S. Kuznetsov, Spietsial'nyie funktsii (Special functions) (Fizmatgiz, Moscow, 1962). 


\title{
ПРО ВПЛ ИВ ЕЛЕКТРОННОЇ СКЛ АДОВОЇ ДЕФОРМАЦЇ̈ І РАТКИ НА ЛОКАЛ ІЗОВАНІ СТАНИ В КРИСТАЛ АХ 3 ДИСЛОКАЦІЯМИ
}

\author{
Р. М. Пелещак ${ }^{1}$, Б. А. Лукіянець ${ }^{2}$ \\ ${ }^{1}$ Дрогобицький педагогічний університет ім.І.Франка, \\ вул. І. Франка, 34, Дрогобич, 293720, Львівська облась, Украйна \\ 2 Державний університет "Львівсъка Політехніка", \\ вул. С. Бандери, 12, Львіб, 290646, Украӥна
}

Отримані раніше результати самоузгодженого розрахунку деформації гратки застосовуються до аналізу електронних локалізованих станів в околі крайової прямолінійної дислокації. Проаналізована поведінка цих станів зале жно від величини електрон-деформаційної взаємодії. Показано, що ступінь залягання локалізованих рівнів немонотонно зале жить від величини такої взаємодії. 